Case Report

\title{
Bilateral Distal Radius Fractures in \\ a 12-Year-Old Boy after Household Electrical Shock: Case Report and Literature Summary
}

\author{
Norman Stone III, Mara Karamitopoulos, David Edelstein, \\ Jenifer Hashem, and James Tucci \\ Department of Orthopaedic Surgery, Maimonides Medical Center, 927 49th Street, 2nd floor, Brooklyn, NY 11219, USA \\ Correspondence should be addressed to Jenifer Hashem; jhashem@maimonidesmed.org
}

Received 30 August 2013; Accepted 26 November 2013; Published 5 January 2014

Academic Editor: John Kortbeek

Copyright (C 2014 Norman Stone III et al. This is an open access article distributed under the Creative Commons Attribution License, which permits unrestricted use, distribution, and reproduction in any medium, provided the original work is properly cited.

Background. Fracture resulting from household electric shock is uncommon. When it occurs, it is usually the result of a fall; however, electricity itself can cause sufficient tetany to produce a fracture. We present the case of bilateral fractures of the distal radii of a 12-year-old boy which were sustained after accidental shock. The literature regarding fractures after domestic electric shock is also reviewed. Methods. An Ovid-Medline search was conducted. The resultant articles and their bibliographies were surveyed for cases describing fractures resulting from a typical household-level voltage (110-220 V, 50-60 Hertz) and not a fall after the shock. Twentyone articles describing 22 patients were identified. Results. Twenty-two cases were identified. Thirteen were unilateral injuries; 9 were bilateral. Proximal humerus fractures were most frequent ( 8 cases), followed by scapula fractures ( 7 cases), forearm fractures ( 4 cases), femoral neck fractures ( 2 cases), and vertebral body fracture (1 case). Eight of the 22 cases were diagnosed days to weeks after the injury. Conclusions. Fracture after electric shock is uncommon. It should be suspected in patients with persistent pain, particularly in the shoulder or forearm area. Distal radius fractures that occur during electrocution are likely due to tetany.

\section{Introduction}

Electricity can damage human tissue in the 4 following ways [1-9]:

(1) disruption of physiologic conduction systems, including cardiac contraction and diaphragm excursion, leading to arrhythmia and apnea;

(2) thermal energy generated by the electrical current;

(3) electroporation of cell membranes occurs leading to a disruption of intracellular ion and protein balance, and ultimately, apoptosis;

(4) mechanical injury due to a fall or forceful muscle contraction.

The degree of electrical injury is dependent on the currant, voltage, duration of contact, tissue resistance, and the path of the current flow through the body $[1,3,4]$.
Initial medical care after electrical injury focuses on the most common sequellae of electrocution: infection of the burn wounds, myonecrosis leading to acute renal failure, cardiac arrest or arrhythmia, pneumonia, nausea, and vomiting $[2,5]$. Whereas fracture during electroconvulsive therapy is a well-established complication described in the psychiatry literature [10-12], fracture after accidental electrical injury is uncommon. When it does occur, it is usually the result of a fall sustained after the shock. Additionally, fractures can occur as a consequence of uncontrolled muscular contraction. A welldescribed example of this kind of injury during electrocution occurs with posterior shoulder dislocations, in which the humeral head is forced posteriorly and superiorly against the acromion, and medially against the glenoid fossa, due to the powerful shoulder girdle musculature. As a result, the humeral head dislocates and then becomes impacted against the bony posterior glenoid rim. This motion results in a fracture defect of the anterior humeral head just medial to the lesser tuberosity (reverse Hill-Sachs) [13, 14]. 


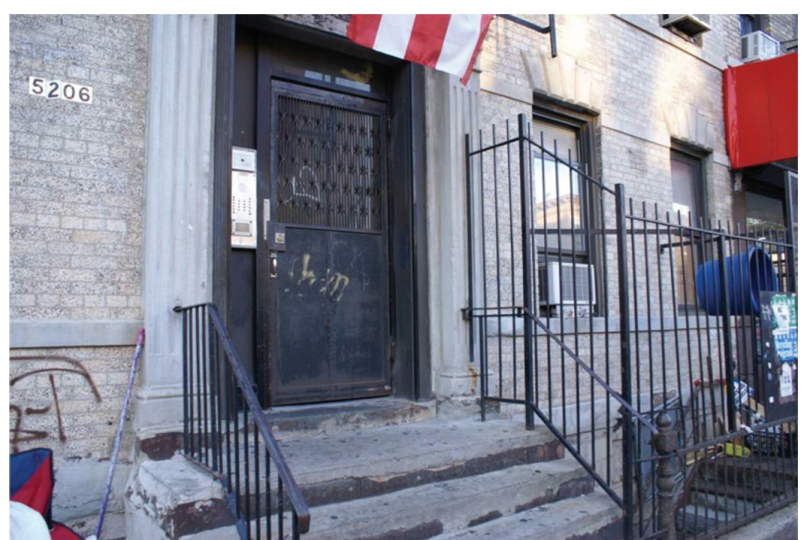

FIGURE 1: The offending door and stair railing.

However, it is possible that the electricity itself can occasionally cause sufficient tetany to produce a fracture. We present the case of bilateral, apex-dorsal, buckle fractures of the distal radii of a 12-year-old boy which were sustained after accidental shock by a faultily-wired apartment entrance door. We further review the literature regarding fractures after domestic electric shock where the fracture appears to have occurred because of the electricity itself.

\section{Case Report}

A 12-year-old boy presented to the Pediatric Emergency Department shortly after receiving an electric shock at a nearby apartment building. As the boy, his mother, and younger brother were waiting outside the building for friends to "buzz them in" (Figure 1), an individual exited the building and held the door open. The mother and younger brother entered without touching the door. As our patient entered the building, he grasped the metal door knob with his left hand while at the same time keeping his right hand on a metal stair railing that was adjacent to the entrance. This action occurred just as the door entry mechanism was activated from upstairs. As a result, the patient sustained an electrical shock inducing upper extremity tetany, prohibiting him from releasing his grip. The shock lasted approximately 5 seconds and was witnessed by the patient's mother. The patient retained consciousness throughout the event and did not fall afterwards.

Initial evaluation in the Emergency Department centered on the potential cardiac, myopathic, and renal aspects of the injury. The patient was admitted for telemetry monitoring in the Pediatric Intensive Care Unit. No arrhythmias were noted. The following morning, the patient complained of bilateral wrist pain. He had mild swelling and erythema, therefore an orthopaedic surgery consult was requested for evaluation.

The child was able to use both hands, favoring the right over the more painful left. There were no burn marks or abrasions, but mild, bilateral, distal radius volar angulation deformities were present. Anteroposterior, lateral, and oblique radiographs of both wrists revealed bilateral, buckletype, apex-dorsal angulated fractures of the distal radial
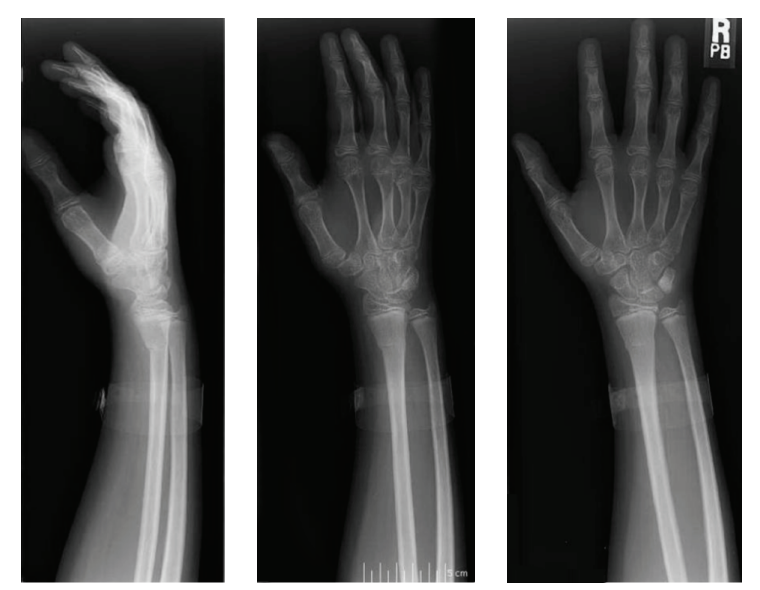

FIGURE 2: Radiographs of right wrist showing apex-dorsal distal radius buckle fracture.
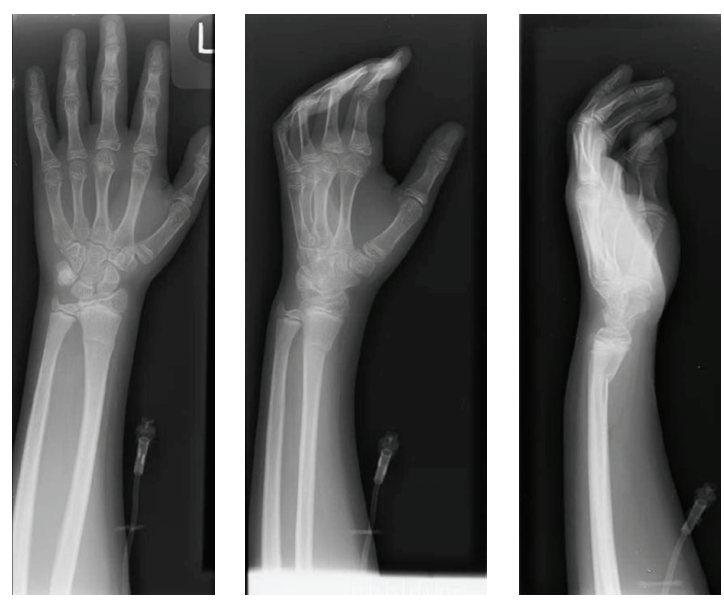

FIGURE 3: Radiographs of left wrist showing apex-dorsal distal radius buckle fracture.

metaphyses (Figures 2 and 3). The patient was placed in bilateral volar splints to reduce wrist motion, preserve hand function, and permit examination of his skin. He was discharged home directly from the PICU on hospital day three and followed an uneventful course to clinical and radiographic healing.

\section{Discussion}

3.1. Most Common Fractures after Electrical Injury. Our literature review identified several case reports describing fractures after electrical injury, but no attempts to inventory all published fractures resulting from domestic electrocution. We identified 21 articles describing 22 cases where a fracture was the result of the electricity itself and not a fall at the time of injury. Nineteen articles were published in English language journals. Two were published in a different language but had English language abstracts available.

Overall, fractures were reported most frequently in the proximal humerus and scapula, as part of the posterior 
TABLE 1: Anatomic distribution of reported fractures after household-voltage electrical injury.

\begin{tabular}{|c|c|c|c|c|}
\hline Bone & Bilateral & Unilateral & Total fractures & References \\
\hline \multicolumn{5}{|l|}{ Forearm } \\
\hline Colles & & 1 & 1 & {$[22]$} \\
\hline Galeazzi & & 1 & 1 & {$[23]$} \\
\hline Greenstick & 1 & & 2 & {$[16]$} \\
\hline Distal radius & & 1 & 1 & {$[24]$} \\
\hline \multicolumn{5}{|l|}{ Shoulder } \\
\hline Proximal Humerus & 3 & 5 & 11 & {$[15,20,26,28-31]$} \\
\hline Scapula & 4 & 3 & 11 & {$[18,19,25,32-35]$} \\
\hline \multicolumn{5}{|l|}{ Vertebrae } \\
\hline Lumbar L4 burst & & 1 & 1 & [17] \\
\hline \multicolumn{5}{|l|}{ Femur } \\
\hline Neck & 1 & 1 & 3 & {$[36,37]$} \\
\hline
\end{tabular}

shoulder fracture-dislocation injury pattern. Next most common were forearm fractures, followed by femoral neck and vertebral body fractures (Table 1).

\subsection{Forearm Fractures after Electrical Injury. We identified} four cases in addition to our patient $[16,22-24]$ of isolated forearm fractures after household electrical injury. Interestingly, three of the four involved 11-year-old girls [16, 22, 23]. Three cases were unilateral [22-24], and one described bilateral injuries [16]. Hostetler and Davis [23] described a girl who grasped the metal doorknob of a lifeguard shack while standing in pooled water. The power cord of a nearby radio was routed under the same door and ran through the same puddle; the girl sustained a unilateral Galeazzi fracture during a 5-10 second tetanic grasp. Similarly, Adams and Beckett [16] recorded the story of a girl who sustained bilateral distal radius buckle fractures while simultaneously switching on the overhead light and grasping a metal hand railing of an outdoor shed. Tucciarone et al. [22] reported a girl who incurred an "incomplete" distal radius fracture who presented with throbbing and tingling in both arms. Finally, Evans and Little [24] described the case of an 84-year-old woman who touched a puddle of water which was in contact with a faulty wire that was involved in an electrical fire; she subsequently sustained a distal radius fracture.

Authors have proposed that the posterior shoulder fracture-dislocation pattern of injury is produced by forceful, sustained, posterior-directed tetany of the deltoid, latismus dorsi, teres major, teres minor, and infraspinatus muscles [25-27]. It is believed that the severity of these injuries occur as a continuum that results from the intensity and duration of muscular contraction. Once the humeral head dislocates posteriorly, the anterior fracture-defect results from the subsequent impaction of the humeral head against the glenoid rim. If the tetany ceases, this remains the extent of injury. However, with further insult the fracture will continue to propagate as the tendinous attachments produce shearing forces to the bone. The humeral head is subsequently avulsed off along with the greater and lesser tuberosities. With continued contraction, the triceps, coracobrachialis, biceps, and deltoid muscles force the humeral shaft fragment superiorly against the acromion, causing further comminution. In this circumstance, it is this combination of both indirect and direct means by which the powerful muscular contractions cause such extensive damage [14].

Our patient, as well as the four other reported patients with forearm fractures, sustained apex-dorsal distal radius fractures. Extrapolating from the shoulder fracturedislocation injury pattern, we suggest that tetanic contraction of flexor carpi radialis and flexor carpi ulnaris directly may produce a moment of sufficient magnitude at the distal radius to produce the observed apex-dorsal fracture pattern, similar to shearing forces experienced during fracture-dislocations.

3.3. Delay in Diagnosis. Several authors describe delays in diagnosis of a fracture after electrical injury of days [15-18] or weeks [19-21] after injury. This likely seems attributable to a delay in presentation of the patient, investigation of potentially greater comorbid sequelae, and the challenge in obtaining a clear history and physical examination on a recently electrocuted patient. Our patient was not diagnosed until his second hospital day. His physical examination demonstrated minimal deformity and he did not report significant pain at his wrists. Thus, his forearms were not imaged until orthopaedic consultation.

\section{Summary}

After electrical injury, care is appropriately focused on the potentially high morbidity sequelae of the injury: cardiac insult leading to arrhythmia, cutaneous burns, and myonecrosis leading to renal failure. Fracture after electrical injury is uncommon and is often not diagnosed until days or weeks after injury. When it does occur, it most frequently involves the shoulder. The mechanism is likely due to the sustained tetanic contraction of powerful muscle groupsthe superoposterior muscles of the shoulder and wrist flexors at the forearm. Because the mechanism by which fractures occur can be quite complex, it is possible that more fractures than previously believed are attributable to tetanic contractures and not the result of a fall itself. Unfortunately, in these circumstances it remains difficult if not impossible to 
differentiate between cause and effect. Therefore, heightened sensitivity to deformity and patient complaints about persistent pain after injury should be evaluated with appropriate radiographs in order to rule out fracture.

\section{Disclosure}

Level of Evidence: therapeutic level IV.

\section{Conflict of Interests}

The authors declare that there is no conflict of interests regarding the publication of this paper.

\section{References}

[1] K. Phillip and G. Germann, "Electrical injury," in Green's Operative Hand Surgery, D. Green, R. Hotchkiss, and W. C. Pederson, Eds., pp. 2179-2183, Churchill Livingstone, 5th edition, 2005.

[2] L. Solem, R. P. Fischer, and R. G. Strate, "The natural history of electrical injury," Journal of Trauma, vol. 17, no. 7, pp. 487-492, 1977.

[3] J. L. Hunt, A. D. Mason Jr., T. S. Masterson, and B. A. Pruitt Jr., "The pathophysiology of acute electric injuries," Journal of Trauma, vol. 16, no. 5, pp. 335-340, 1976.

[4] B. I. Tropea and R. C. Lee, "Thermal injury kinetics in electrical trauma," Journal of Biomechanical Engineering, vol. 114, no. 2, pp. 241-250, 1992.

[5] F. C. DiVincenti, J. A. Moncrief, and B. A. Pruitt Jr., "Electrical injuries: a review of 65 cases," Journal of Trauma, vol. 9, no. 6, pp. 497-507, 1969.

[6] R. C. Lee, "The pathophysiology and clinical management of electrical injury," in Electrical Trauma, R. C. Lee, E. G. Cravalho, and J. F. Burke, Eds., pp. 33-58, Cambridge University Press, 1992.

[7] R. C. Lee and M. S. Kolodney, "Electrical injury mechanisms: dynamics of the thermal response," Plastic and Reconstructive Surgery, vol. 80, no. 5, pp. 663-671, 1987.

[8] R. C. Lee and M. S. Kolodney, "Electrical injury mechanisms: electrical breakdown of cell membranes," Plastic and Reconstructive Surgery, vol. 80, no. 5, pp. 672-679, 1987.

[9] J. Singerman, M. Gomez, and J. S. Fish, "Long-term sequelae of low- voltage electrical injury," Journal of Burn Care and Research, vol. 29, no. 5, pp. 773-777, 2008.

[10] L. Kolb and V. H. Vogel, "The use of shock therapy in 305 mental hospitals," The American Journal of Psychiatry, pp. 90-100, 1942.

[11] E. Samuel, "Some complications arising during electrical convulsive therapy," The British Journal of Psychiatry, vol. 89, pp. 81-83, 1943.

[12] J. P. Kelly, "Fractures complicating electro-convulsive therapy and chronic epilepsy," The Journal of Bone and Joint Surgery. British, vol. 36, no. 1, pp. 70-79, 1954.

[13] R. B. Blasier and J. K. Burkus, "Management of posterior fracture-dislocations of the shoulder," Clinical Orthopaedics and Related Research, no. 232, pp. 197-204, 1988.

[14] J. L. Shaw, "Bilateral posterior fracture-dislocation of the shoulder and other trauma caused by convulsive seizures," The Journal of Bone and Joint Surgery. American, vol. 53, no. 7, pp. 1437-1440, 1971.
[15] I. Aktas and K. Akgun, "Frozen shoulder development secondary to proximal humerus fracture and supraspinatus tendon tear following electrical injury," Europa Medicophysica, vol. 43, no. 4, pp. 469-473, 2007.

[16] A. J. Adams and M. W. Beckett, "Bilateral wrist fractures from accidental electric shock," Injury, vol. 28, no. 3, pp. 227-228, 1997.

[17] W. A. van den Brink and O. van Leeuwen, "Lumbar burst fracture due to low voltage shock. A case report," Acta Orthopaedica Scandinavica, vol. 66, no. 4, pp. 374-375, 1995.

[18] J. L. Dumas and N. Walker, "Bilateral scapular fractures secondary to electrical shock," Archives of Orthopaedic and Trauma Surgery, vol. 111, no. 5, pp. 287-288, 1992.

[19] J. P. Simon, I. Van Delm, and G. Fabry, "Comminuted fracture of the scapula following electric shock. A case report," Acta Orthopaedica Belgica, vol. 57, no. 4, pp. 459-460, 1991.

[20] A. H. C. Tan, "Missed posterior fracture-dislocation of the humeral head following an electrocution injury to the arm," Singapore Medical Journal, vol. 46, no. 4, pp. 189-192, 2005.

[21] M. I. Salem, "Bilateral anterior fracture-dislocation of the shoulder joints due to severe electric shock," Injury, vol. 14, no. 4, pp. 361-363, 1983.

[22] L. Tucciarone, T. Sabbi, A. Colasanti, and S. Papandrea, "Colles' fracture in a girl after fulguration," La Pediatria Medica $e$ Chirurgica, vol. 19, no. 1, pp. 71-72, 1997 (Italian).

[23] M. A. Hostetler and C. O. Davis, "Galeazzi fracture resulting from electrical shock," Pediatric Emergency Care, vol. 16, no. 4, pp. 258-259, 2000.

[24] R. J. Evans and K. Little, "Fracture due to shock from domestic electricity supply," Injury, vol. 22, no. 3, pp. 231-232, 1991.

[25] M. Rana and R. Banerjee, "Scapular fracture after electric shock," Annals of the Royal College of Surgeons of England, vol. 88, no. 2, pp. 3-4, 2006.

[26] P. H. O'Flanagan, "Fracture due to shock from domestic electricity supply," Injury, vol. 6, no. 3, pp. 244-245, 1975.

[27] T. Tarquinio, M. E. Weinstein, and R. W. Virgilio, "Bilateral scapular fractures from accidental electric shock," Journal of Trauma, vol. 19, no. 2, pp. 132-133, 1979.

[28] M. Lenghi and J. S. Ranyal, "Posterior fracture-dislocation of the shoulder joint," Clinical Orthopaedics and Related Research, no. 250, pp. 310-311, 1990.

[29] F. M. Saunders and M. R. James, "Bilateral humeral head fractures following an electric shock," Journal of Accident \& Emergency Medicine, vol. 14, no. 4, p. 225, 1997.

[30] D. T. Stueland, P. Stamas Jr., T. M. Welter, and D. A. Cleveland, "Bilateral humeral fractures from electrically induced muscular spasm," Journal of Emergency Medicine, vol. 7, no. 5, pp. 457-459, 1989.

[31] L. Zynda and K. Skiba, "Fracture of both humeral bones after electrocution," Chirurgia Narzadów Ruchu i Ortopedia Polska, vol. 56, no. 1-3, pp. 64-65, 1991 (Polish).

[32] W. Chao, Y. Lin, W. Hsu, C. Fang, C. Yang, and K. Huang, "Severe injuries associated with low voltage electrical injuries," The Journal of Plastic Surgical Association R.O.C., vol. 13, no. 4, pp. 284-290, 2004.

[33] D. J. Dave, S. R. Koka, E. Ruffell, and J. C. D’Arcy, "Bilateral simultaneous glenoid fractures," Injury, vol. 25, no. 3, pp. 202203, 1994.

[34] B. P. Kotak, O. Haddo, M. Iqbal, and H. Chissell, "Bilateral scapular fractures after electrocution," Journal of the Royal Society of Medicine, vol. 93, no. 3, pp. 143-144, 2000. 
[35] B. John, F. Poyner, and V. Holloway, "Bilateral scapular fractures following low voltage electrocution," Grand Rounds, vol. 4, pp. 10-12, 2004.

[36] D. Drinnen and B. L. Enderson, "Electrical injury as a cause of fracture," Journal of the Tennessee Medical Association, vol. 88, no. 8, p. 313, 1995.

[37] M. A. Shaheen and N. A. Sabet, "Bilateral simultaneous fracture of the femoral neck following electrical shock," Injury, vol. 16, no. 1, pp. 13-14, 1984. 


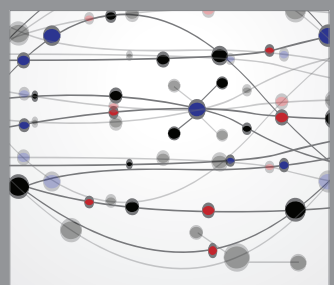

The Scientific World Journal
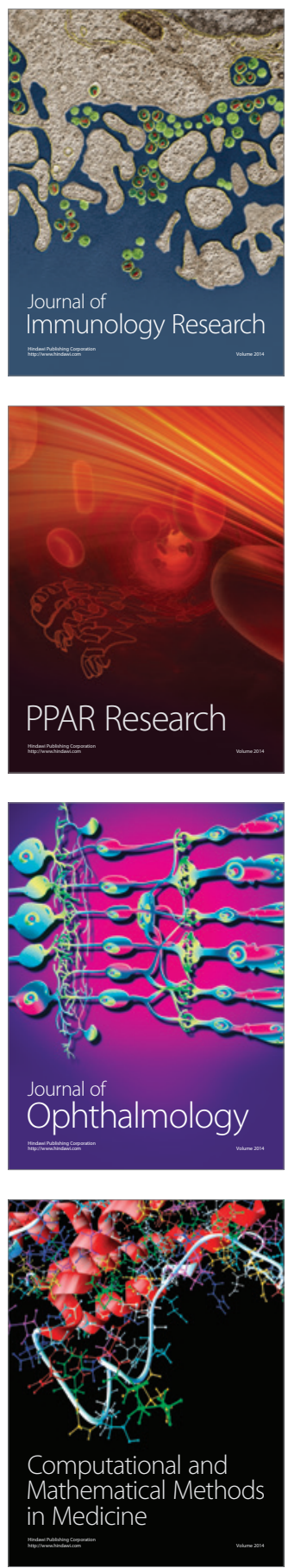

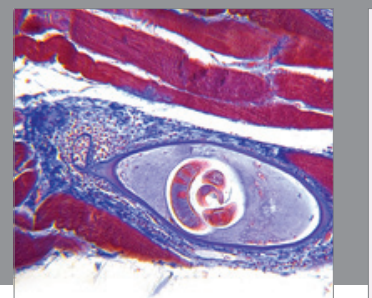

Gastroenterology

Research and Practice
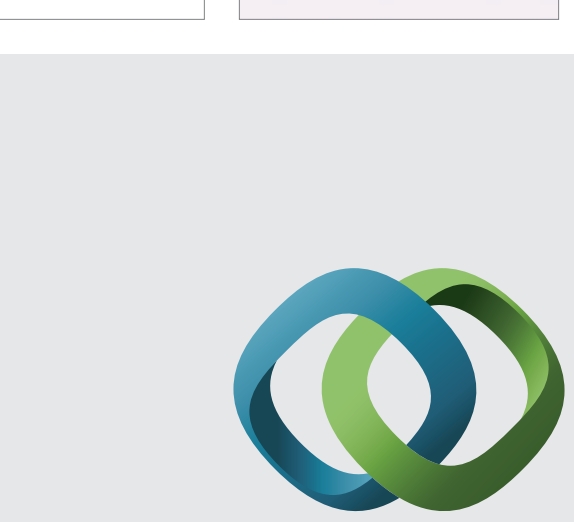

\section{Hindawi}

Submit your manuscripts at

http://www.hindawi.com
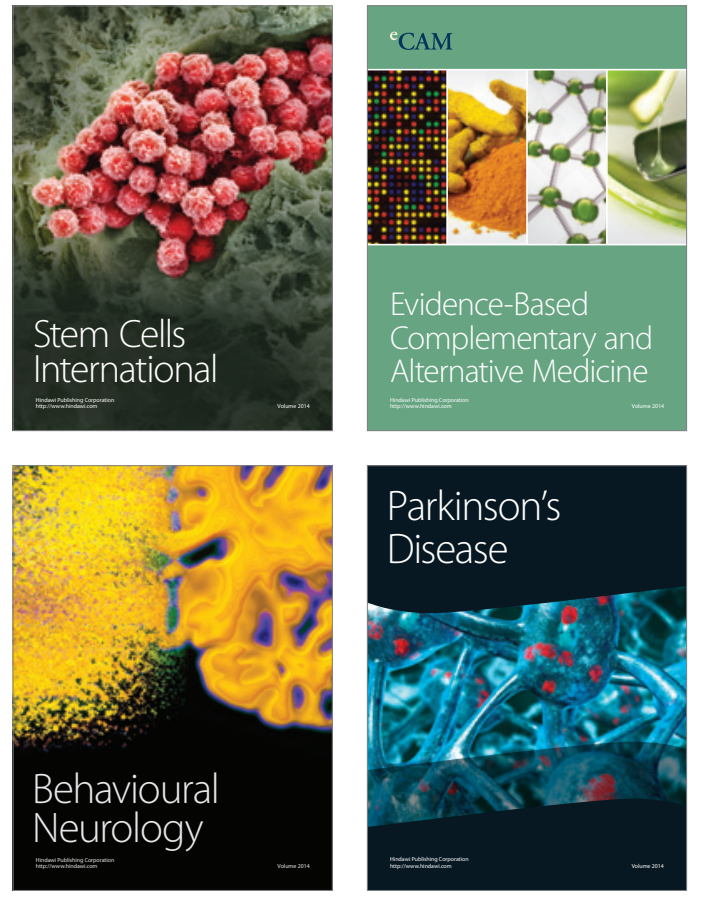
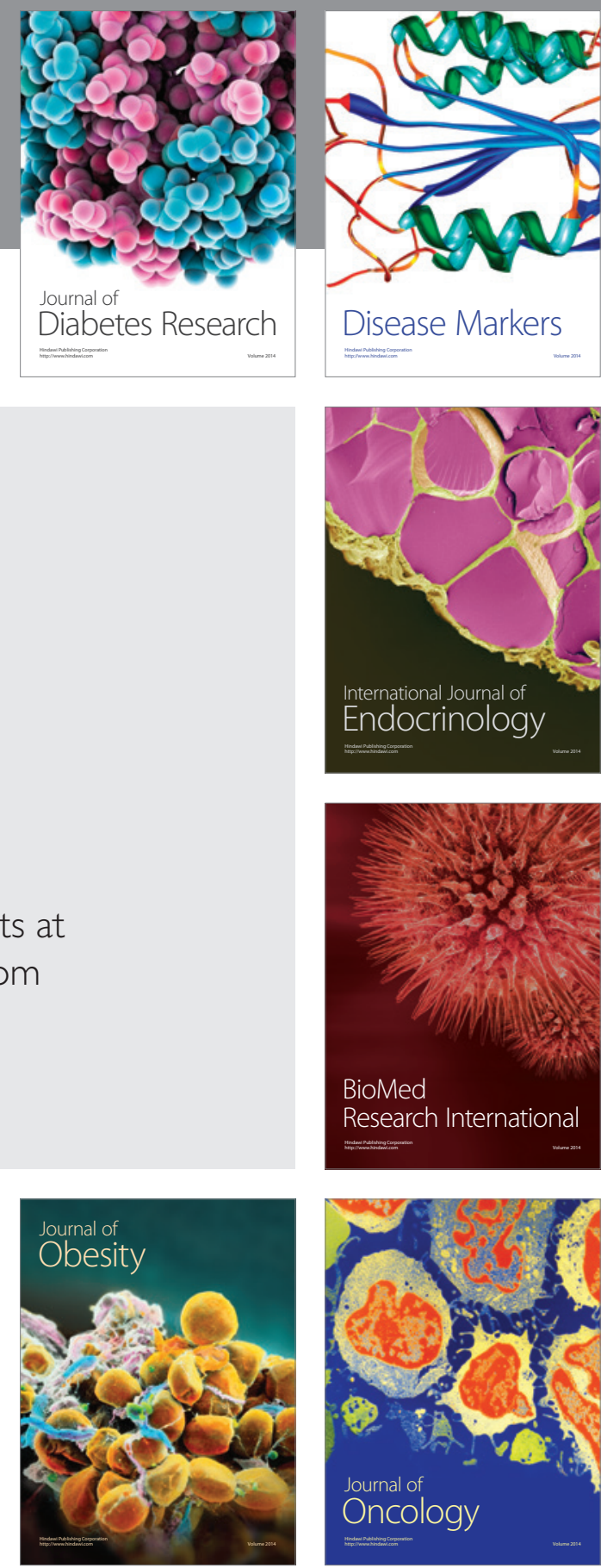

Disease Markers
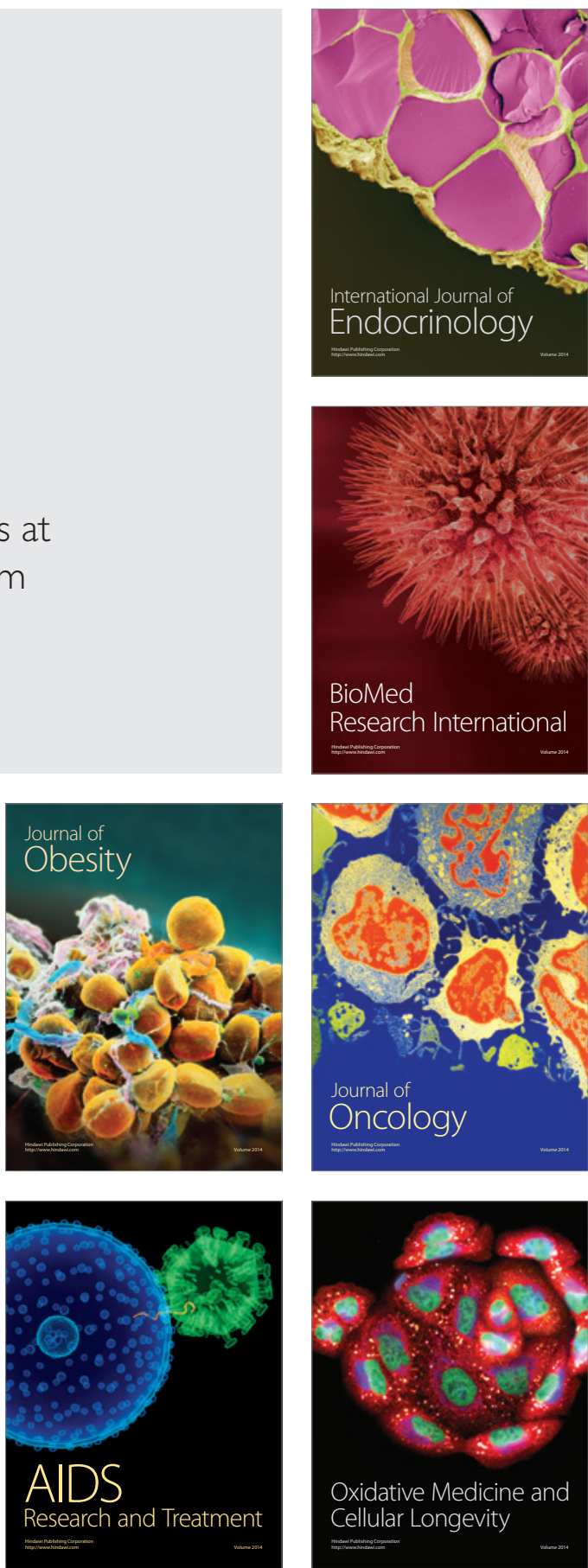